\title{
Character Archetypes: Aesthetic Values in Character Design in Malaysia`s Animated Films
}

\author{
Dahlan Abdul Ghani, Asyraf Zaki bin Mohd Sobri
}

\begin{abstract}
Animation defined as a process which giving inanimate object or images appear to be moved. Today, the technology has advanced to another level which animators using computer-generated imagery (CGI) to animate. The aim of this research is to introduce to people about the aesthetics value in character design. In animated film, it must be a character to roll as something that can successfully give the message, feeling, and mood in a situation. So, the character must have the aesthetic value through strong physical appearance based on his or her colour patterns, body language, and shapes to express them. For example, in Malaysia we have many iconic characters in animated series that succeed in portraying the aesthetics value based on what they wanted to deliver like Upin Ipin, Boboi Boi, Keluang Man and Anak-anak sidek. However, not all viewers see the difference. Thus, by making this research, it will guide them to be more intuitive and can differentiate among characters in any movies.
\end{abstract} CGI).

Key words: Character design, aesthetic value, animation,

\section{BACKGROUND OF THE STUDY}

Animation is a process where images or objects are manipulated together and giving illusion to audience. During previous era, animators are struggled to make animation because they don't have enough equipment to ease them. For example, in two-dimensional (2D) animation, they need to draw every single frame without depending so much on their tools. When technology thrived, animators mostly prefer using computer-generated imagery (CGI) rather than traditional method because it's easy to use. In CGI, animators can create their own virtual world in $2 \mathrm{D}$ or three-dimensional (3D) form based on their preference.

In animated films, a character sometimes used to roll as someone or objects that can express the character's personalities. The character must be attractive and appropriate to the story, background and the style of the film. For instance, if we wanted to design a character for horror movie, maybe we need to make it look more gloomy appearance and not using too much bright colours, unless we made it on purpose.

\footnotetext{
Revised Manuscript Received on September 10, 2019.

Dahlan Abdul Ghani, Universiti Kuala Lumpur, Malaysian Institute of Information Technology, Jalan Sultan Ismail, Kuala Lumpur, Malaysia. (Email: dahlan@unikl.edu.my)

Asyraf Zaki bin Mohd Sobri, Universiti Kuala Lumpur, Malaysian Institute of Information Technology, Jalan Sultan Ismail, Kuala Lumpur

(Email: xxasyrafxzakixx@gmail.com)
}

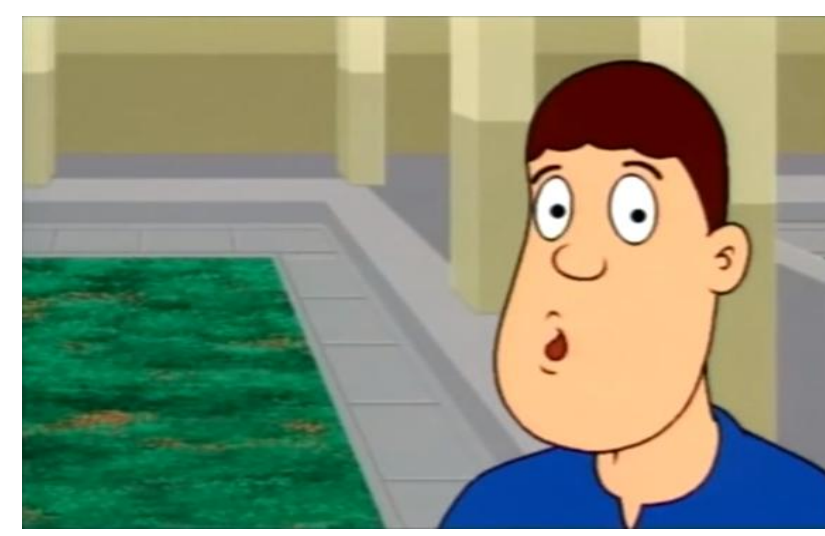

Figure 1.1 Main character in Keluang Man without his suits

2D Character like Borhan from Malaysia 's animated series Keluang Man (see Figure 1.1), they emphasized the personality of the character in goofy-look because they wanted to blend the character with action comedy story but what if the character were design in $3 \mathrm{D}$, is the result will be the same?

Charlie Chaplin (n.a) stated, "I had no idea of the character. But the moment I was dressed, the clothes and the make-up made me feel the person he was. I began to know him, and by the time I walked onto the stage he was fully born." By other means, the expression of a character is not located on the medium of animation used but it's on the character itself.

The viewers in Malaysia are clueless that character's appearance plays important role to attract them watching the animation. They just simply say weather its good or bad Actually, we should expose the intro of the aesthetic values in character design so that could give them different perception about character design.

\section{LITERATURE REVIEW}

\subsection{Introduction Of Character Design}

Character design is a form illustrated by a designer and used for some purpose like in animated films, games, and comics. The aesthetics value arises when it's done with passion. According to a study by Chris Oatley (2018), I almost never meet an aspiring or pre-professional character designer who actually understands the job. Typically, these artists rush into the design without getting to know the character. So, the out come will never be as pure as what it should be in other means, the character will lack some of the characteristic value. 


\subsubsection{Characteristic Springs From Creator}

Choosing a colour palette when creating a character is vital, not only in order to produce a pleasing aesthetic, but also how it will influence the viewing audience (Marika Nieminen,2017). There are many approaches in creating good character design. "An animator is an actor with a pencil", goes the oldest and truest animation cliché. Not "a draftsman that acts", but first and foremost - an actor. If you're trying to tell a story through a character, inevitably you're an actor. The only question is whether you are a good actor or a bad one (Doron A. Meir,2015). So, if a character involved in a situation, the acting should happen, then it depends on whether the director is good or bad one. According to Britma (2013), character's personality structure is revealed in his/her body language, a narrative field capable of representing what is happening in the psyche and always embedded in an individuality. Postures and gestures are also strongly related to the cultural background of a character. Another related study done by (Sergio Aragones) stated that sometimes, you start with the drawing and then the gag comes to you in the middle of it. That is when you start working on the solution of the gag, which is composition, placing, equilibrium, and character design.According to a study done by Ted Naifeh (n.a.) Character design, like story design, requires a hook to grab the reader's attention. According to Joe Quesada (2010) "At that point Jimmy and I were drawing from our own lives. There are elements of Ashley Quinn (the character) that distinctly me, and there are elements that are distinctly Jimmy. For instance, Ash`s (the character) mom was modelled after Jimmy's mom, and parts of Ashley's personality were definitely parts of mine. We can define that the character personalities should be implemented in designing phase so that it will boost the attraction.

\section{RESEARCH METHODOLOGY \& RESULTS}

\subsection{Psychology (Body Language)}

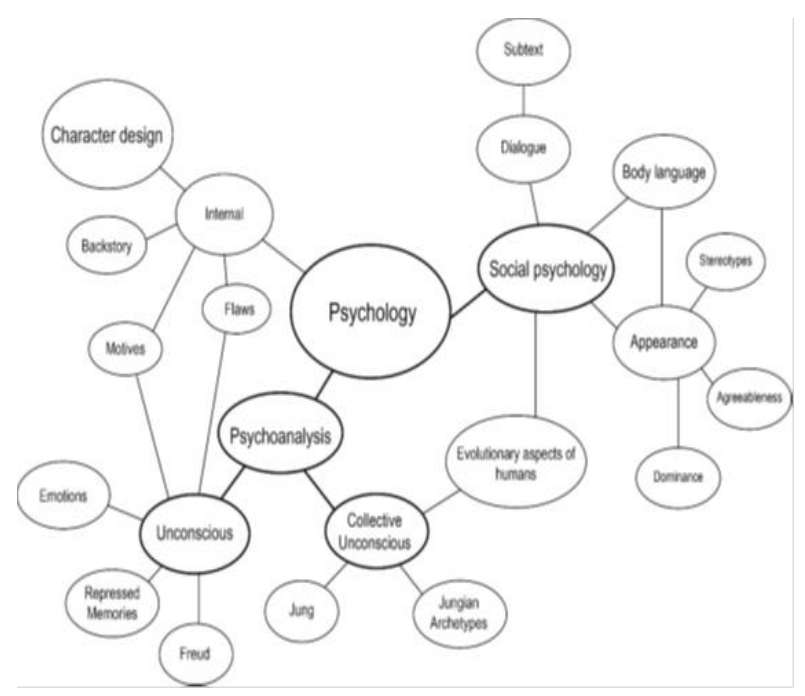

3.1 Mind map for Psychology analysis (Nieminen,2017)

The theory above in figure 3.1 shows some elements of psychology that can be applied in character design based on their personality because animated characters also have emotions, expressions and body language that similar to real human. Even when animating a character that resembles to animals, animators will put some of human body language so that the emotion can be understand by human (see Figure 3.2). According to Stanchfield (2009), anthropomorphic characters are a step removed from human characters and require a certain degree of imitation or impersonation of human traits in order to succeed. This means the real theory of character personality is actually used in character design for making the character to be understandable to people.
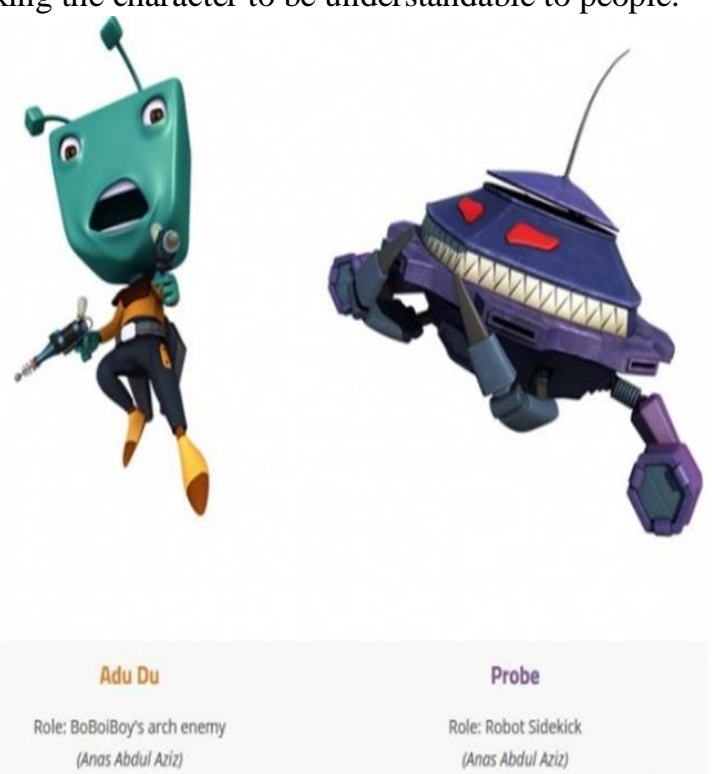

\subsection{Adu Du (left) and Prob (right) from Boboiboy animated film}

Evil character with alien shaped like Adu Du (see Figure 3.2), where his mission is to conquer the world. He and his minions together struggle to fight Boboiboy and the gang to accomplish the mission. Because of this reason, the character is designed with evil-shaped and packaged with angry manner. To animate these 3-Dimensional (3D) characters, animators need to understand accurately about body language because they need to rig the character from every single frame so that it will not look stiff in the end Another study from Chapman (2010), Michelangelo considered the torso as "the key expressive area of the body".

Based on body figure, torso is the new posing approach centred on the body and the flow of the body as well triggers from the centre point of human body. Other quotes from Leonardo da Vinci (n.a.), "Represent your figures in such action as may be fitted to express what purpose in their minds; otherwise your art will not be good". It is absolutely true whereas animator, they need to feel the character and understand them until they can imagine that the character is very real. For them, designing expressions might be a challenging process because it may end up people don't understand what is the expressions and body language wanted to tell about. Consequently, if they are just only focusing facial expression, it is not enough if the character is lack of body language. So, the audience maybe will see the

Blue Eyes Intelligence Engineering

\& Sciences Publication

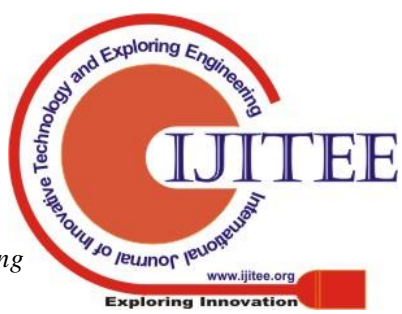


major effect from the character on the screen but how a For character designers, they are using the same method by knowing what expression should be exaggerated, what appropriate colours should be used, what shapes and others. When all aspects are perfect, then the character will reap a mighty success.

In animated films, there will be various of character personalities based on imagination of artists. Personalities give the attitude to the character for example face expression, by adding and exaggerating on it, the character will become more alive and the expression can vividly understandable. It is common conceptions that character designers have used successfully for a long time. Adding further information such as value, colour and light can definitely re-enforce characteristics as well.

\subsection{Color Value}

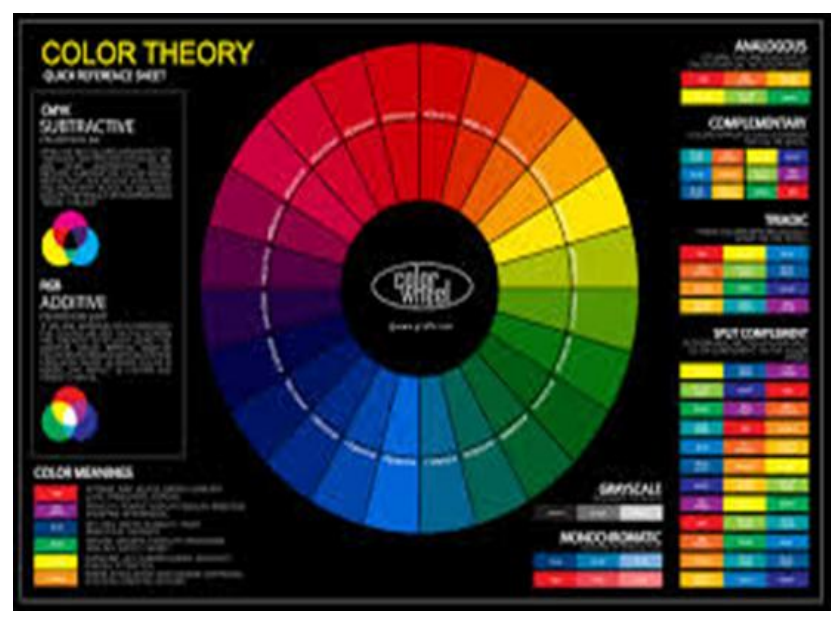

3.2 Sample of colour wheels. The colours smoothly blend together with another colour and showing gradient in between.

Colour is very important to show the character mood and personality specially to differentiate the protagonist and antagonist character (see Figure 3.3). We always see in many films for protagonist character to be more appealing and more cheerful than antagonist. According to Wassily Kandinsky (n.a.), colour transmits and translates emotion. $\mathrm{He}$ also believed colours have expressions and have their own qualities:

1. Yellow - warm, exciting, happy

2. Blue - deep, peaceful, supernatural

3. Green - peace, stillness, nature

4. White - harmony, silence, cleanliness

5. Black - grief, dark, unknown

6. Red - glowing, confidence, alive

7. Orange - radiant, healthy, serious character is determined may be differ from person to person.
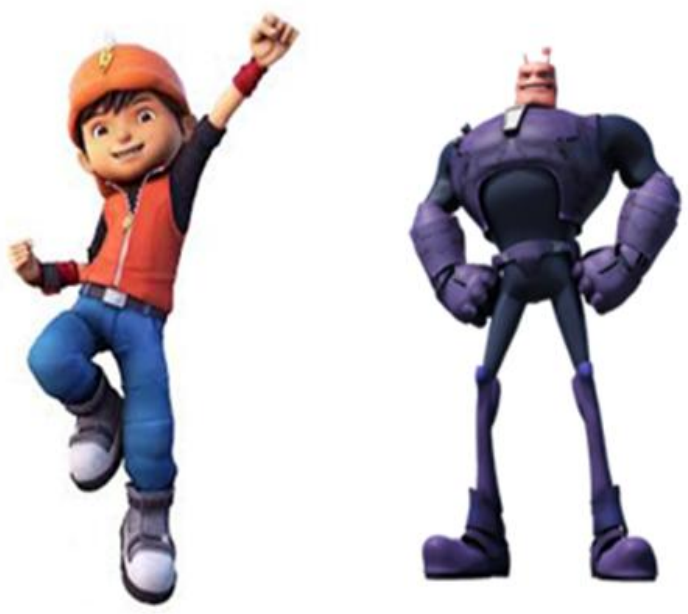

Figure 3.3 Boboiboy, protagonist character (left) and Bora Ra antagonist character

These colour theories are also used in the process of designing a character (see Figure 3.2). They will determine colour using colour scheme, so that they will know what appropriate colour should be used for the character. As we can see the colour explanation above we can say that Boboiboy character (see Figure 3.3) has combination of yellow, orange, red, and blue which means there are more of bright colour than dark colour like blue, black and etc. By using brighter colour, the qualities of it will unleash and people can easily recognize the character as a protagonist.

\subsection{Enhancing Character By Implementing The Culture} Value

To successfully enhancing for designing a product in the creation of a character, culture also is one of the best spices to show the mood and give the vibes to character itself. Without it, the audience can never know the uniqueness of the environment. For example, if the background landscape sets up in the remote village somewhere in Malaysia, but the character doesn't give the identity of it, so the viewers may not recognize and feel the story precisely.

"There are no easy answers in designing game character that have appeal across culture groups but some suggestions that may help aim character designs in a direction that supports transculture appeal” (Katherine Isbister,2007).

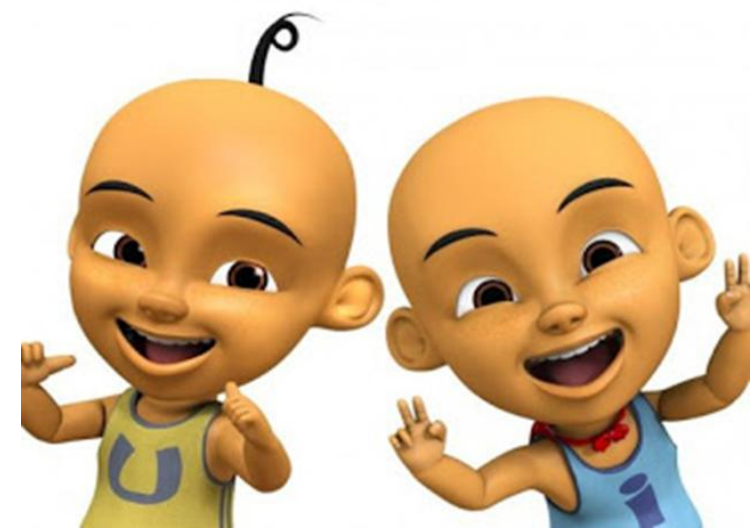

Figure 3.4 Main character of Upin Ipin

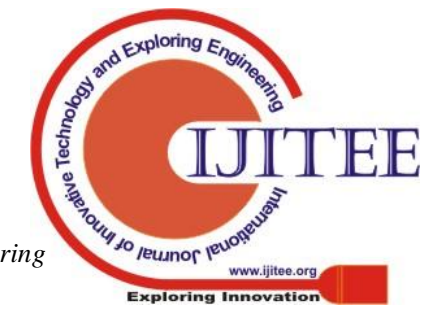


Another the best example is Upin Ipin. It is an animated film that originated from Malaysia (see Figure 3.4). We can barely recognize them as Malaysian culture by just only see the characters without looking at all their landscape design storytelling and etc. The way they dressed them are just like what people would wear and matched the situation. Also, culture is very synonym to unity (see Figure 3.5). According to Zainal Abidin Ahmad Mazlan Zulkifly (2006), "Without unity, the country will be exposed to a variety of weaknesses and threats that can undermine the sovereignty of the religion itself ". In other means, if we look at design perspective, we also should be careful when designing things that sometimes may accidently hurting other cultures without consent.

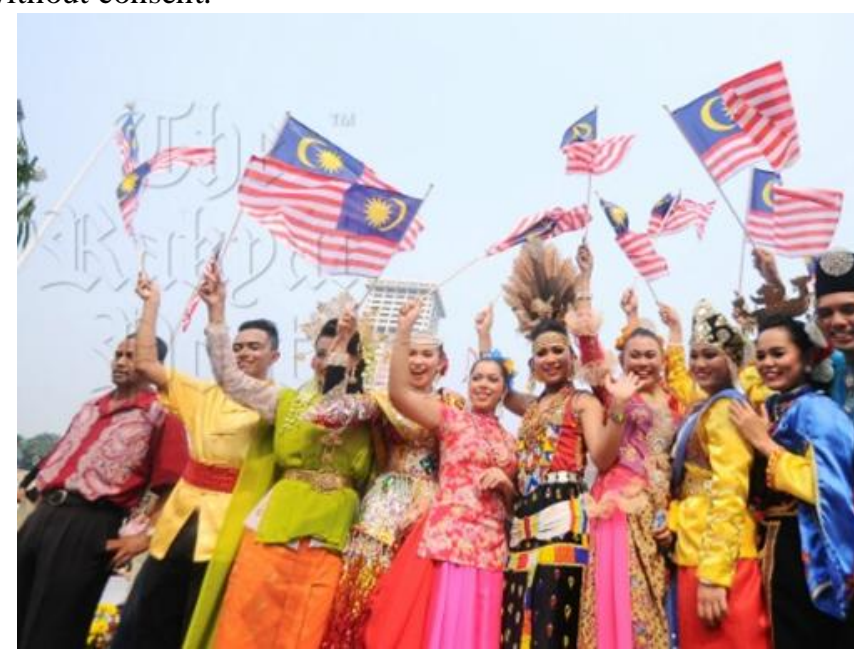

Figure 3.5 Vary cultures of the different people of Malaysia.

\section{REFERENCES}

1. Aragonés, S. (2018 ). sergioaragones (homepage). Retrieved from sergioaragones: https://sergioaragones.com/ask-sergio/

2. Aragones, S. (n.d.). Character Design Quotes. Retrieved from azquotes: https://www.azquotes.com/quotes/topics/characterdesign.html

3. Bancroft, T. (2016, February 29). Blog. Retrieved from Taught by A Pro: http://taughtbyapro.com/what-ischaracter-design/

4. Burgerman, J. (2017, September 07). topics. Retrieved from creativebloq: https://www.creativebloq.com/character-design/tips5132643

5. Curtis, G. (2007). The Spider-man Chronicles. San Francisco .

6. Design, B. (2013-2015). Pychological Character Design. Retrieved from BRITMA DESIGN: http://www.britmadesign.com/services/aestheticcharacter-design/

7. Fonseca, J. A. (September 2015). Character Body Expression.

8. Harris, W. (2013, January 18). creativebloq. Retrieved from

https://www.creativebloq.com/animation/top-40-

character-design-tips-part-2-human-based-characters1132742

9. How Colour Communicates Meaning. (2009). Retrieved from treehouse: https://blog.teamtreehouse.com/howcolour-communicates-meaning
10. Iveta. (2018). GraphicMama Home. Retrieved from GraphicMama : https://graphicmama.com/blog/flatdesign-character-inspirational-examples/

11. Meir, D. A. (2015). animationarena. Retrieved from animationarena: http://www.animationarena.com/actingand-animation.html

12. Naifeh, T. (n.d.). Brainy quotes. Retrieved from Brainy quotes:

https://www.brainyquote.com/quotes/ted_naifeh_696449

13. Nieminen, M. (2017). Pychology in Character Design.

14. Oatley, C. (2018). Good Character Design Goes Deep. Retrieved from ChrisOatley: https://chrisoatley.com/character-design-goes-deep/

15. Quesada, J. (2010). In J. Quesada, The Marvel Art of Joe Quesada (p. 15).

16. Sandu, B. (2017). Character Design: Tips On How To Design A Character. Retrieved from designyourway: https://www.designyourway.net/blog/graphicdesign/character-design/

17. Syafiq, M. A. (2015, 12 20). Animasi Upin dan Ipin : Menyemai Semangat Perpaduan di Malaysia. Retrieved from class of $x$ : http://apaituilmu.blogspot.com/2015/12/animasi-upindan-ipin-menyemai-semangat.html

18. Wei, K. S. (2014, August 4 ). Psychology of Game Characters Design. Retrieved from Prezi: https://prezi.com/djdjludkjlrt/psychology-of-gamecharacters-design/

19. WEILAND, K. (2011, FEBRUARY 20). 5 Ways to Write Character Thoughts Worth More Than a Penny. Retrieved from helping writers become authors: https://www.helpingwritersbecomeauthors.com/5-waysto-write-character-thoughts/. 